\title{
Research on the Relationship between Gratitude, Consciousness, Adaptability and Coping Style of Contemporary College Students
}

\author{
Ying Bao \\ Xi'an University of Technology \\ Xi'an, China
}

\begin{abstract}
In order to explore the relationship between psychological status of college students' gratitude, their adaptability and coping mode, college students were investigated with College Students' Gratitude Scale, Chinese College Students' Adaptability Scale and Coping Style Questionnaire. The results show that: on the whole, college students have good gratitude accomplishment, but it still needs to be further promoted. There are differences in gratitude psychology regarding different grades and different genders, while there is no difference in gratitude psychology between the only-child and non-only child; There is a correlation between gratitude and coping style, among which negative correlation exists between coping style and the density, width, and depth of gratitude, and there is positive correlation between coping style and frequency of gratitude. There is a significant positive correlation between gratitude and adaptability, and an effective regression equation is established. Gratitude has good predictive effect for adaptability.
\end{abstract}

Keywords-gratitude; adaptability; coping style; college students

\section{INTRODUCTION}

The Chinese nation has a fine tradition of "being grateful", which is a virtue that the Chinese people need to inherit and carry forward. In excellent traditional culture of China, there are many thoughts of gratitude, such as giving me peach and repaying the plum and don't think when giving and don't forget when receiving, and so on, all reflecting the thought of gratitude. These traditional moral cultures inherited and developed for thousands of years, edify and infect human development and progress and shape the human civilization. Some scholars have said that there is one of the deepest expectations in human nature, which is to be appreciated. Gratitude is also human nature that is innate and indelible in the process of development in future. It is the embodiment of conscience, the philosophy of dealing with human relations, the attitude towards life and work, and the great wisdom that is indispensable in the continuous development of human beings. Cultivating the gratitude consciousness of college students can make college students have more positive feelings respect the life, and know how to be grateful. The problem of college students' adaptability has always been the focus of people's attention as well as an important research topic for researchers. From the perspective of sociology, Professor Jia Xiaobo divides the content of adaptation into three categories: the adaptation of social life environment, the adaptation of social roles and the adaptation of social activities. From the psychological point of view, some scholars believe that adaptation is the process of changing brought by the interaction between individuals and the environment. It is a dynamic process of individual internalization as well as the process of individuals making a positive response to the environment and establishing a balanced relationship with it. [2] In the existing studies, the western scholars mainly focus on the research on role adaptation, cognitive adaptation, and interpersonal adaptation and so on. Domestic scholars mainly study the adaptation of college students from the aspects of learning adaptation, life adaptation, professional adaptation, interpersonal adaptation and adaption to social roles. Coping style is the cognitive and behavioral mode adopted by individuals in the face of pressure and frustration. [3] In the process of psychological stress, it is an important mediating factor. The coping style adopted by the individual directly influences the nature and intensity of the stress response, and also regulates the relationship between the stress response and the stress results. The differences in cognition, attitude and behavior of individual in the face of stress also constitute the differences of coping style. Therefore, choosing a good balance between the development of individual physical and mental health and stressor mainly depends on using appropriate coping style, adjusting and reliving individual pressure, and maintaining individual physical and mental health development. On the types of coping style, different researchers put forward their own views according to different perspectives of theory and practice.

The purpose of this study is to explore the relationship between psychological condition of college students gratitude and their adaptability and coping style. It is significant to cultivate college students' gratitude consciousness, choose coping style to deal with stress and enrich the study of college students' adaptability. 


\section{OBJECTS AND METHODS}

\section{A. Object of Study}

The objects of study are selected randomly from the freshmen to seniors of five universities, including Northwest Agriculture and Forestry University, Shaanxi Normal University, Xi'an International Studies University, Xi'an University of Technology and Northwest University of Political Science and Law, with a total of 640 students. There are 578 valid questionnaires, with the effective rate of $90.3 \%$.

\section{B. Research Tools}

1) College Students' Gratitude Scale: The College Students' Gratitude Scale is a kind of self-report inventory developed by Ma Yunxian and Hu Yan, which is composed of four sub-scales, representing the width, depth, concentration and frequency of gratitude respectively. The five-point scoring method is adopted, including four reverse scoring items. The total scores and sub-scales scores are used as evaluation indexes. The coefficient a of the scale is between 0.554 and 0.7808 , which has high reliability and validity.

2) Chinese College Students' Adaptability Scale: The Chinese College Students Adaptability Scale (CCSAS) is compiled by the task group of the Ministry of Education on the evaluation of college students' mental health system. The scale is composed of seven dimensions and 60 questions. The five-point scoring method is adopted and the scores of different dimensions and the total scores are taken as the measurement indexes. The higher the total scores are, the better the adaptability is. [5] The scale has high reliability and validity and the internal consistency coefficient of the scale is 0.93 , showing the high validity and strong stability, which can reflect the adaptation condition of college students in school life.

3) Coping Style Questionnaire: The Coping Style Questionnaire is designed by Xiao Jihua, which is used to explain the types of coping style and behavior characteristics of different individuals or groups, compare the differences of coping behavior among different individuals and groups, analyze the reasons, and then indirectly reflect the maturity degree of their psychological development. [6] The questionnaire has six dimensions, composed of 62 questions, with high reliability and validity. The correlation coefficients of the six coping factors in the questionnaire are between 0.62 and 0.72 .

\section{Statistical Methods}

SPSS 21.0 statistical software is used to analyze the data. The statistical methods are: descriptive statistical analysis, analysis of variance, correlation analysis and regression analysis.

\section{RESULTS AND ANALYSIS}

\section{A. Psychological Status of College Students' Gratitude}

TABLE I. Basic Situation of College Students' Gratitude

\begin{tabular}{|c|c|l|l|}
\hline & $\begin{array}{c}\text { mean } \\
\text { value }\end{array}$ & $\begin{array}{l}\text { standard } \\
\text { deviation }\end{array}$ & $\begin{array}{l}\text { Number } \\
\text { of items }\end{array}$ \\
\hline total score of gratitude & 55.28 & 6.96 & 14 \\
\hline density of gratitude & 20.42 & 2.57 & 5 \\
\hline width of gratitude & 12.27 & 1.96 & 3 \\
\hline frequency of gratitude & 11.54 & 2.04 & 3 \\
\hline depth of gratitude & 11.06 & 1.89 & 3 \\
\hline
\end{tabular}

TABLE II. TEST FOR THE DIFFERENCES IN DIFFERENT DIMENSIONS REGARDING DIFFERENT GENDERS AND ONLY CHILD OR NOT (T)

\begin{tabular}{|c|c|c|c|c|}
\hline & gender & sig & Only-child or not & sig \\
\hline total score of gratitude & 2.564 & 0.110 & 0.455 & 0.501 \\
\hline density of gratitude & 0.666 & 0.415 & 0.156 & 0.693 \\
\hline width of gratitude & 3.033 & 0.082 & 0.765 & 0.382 \\
\hline frequency of gratitude & $6.978 * *$ & 0.009 & 0.026 & 0.871 \\
\hline depth of gratitude & 2.583 & 0.109 & 0.571 & 0.450 \\
\hline
\end{tabular}

TABLE III. TEST FOR DIFFERENCES IN GRATITUDE OF STUDENTS FROM DIFFERENT GRADES IN DIFFERENT DIMENSIONS (F)

\begin{tabular}{r|l|l|l|l|l}
\hline & $\begin{array}{l}\text { total } \\
\text { score of } \\
\text { gratitude }\end{array}$ & $\begin{array}{l}\text { density } \\
\text { of } \\
\text { gratitude }\end{array}$ & $\begin{array}{l}\text { width of } \\
\text { gratitude }\end{array}$ & $\begin{array}{l}\text { frequency } \\
\text { of } \\
\text { gratitude }\end{array}$ & $\begin{array}{l}\text { depth of } \\
\text { gratitude }\end{array}$ \\
\hline Grade & $4.915 * *$ & $3.693 *$ & $3.137 * *$ & $5.464 *$ & $3.129 *$ \\
\hline
\end{tabular}

The condition of college students' gratitude is shown in "Table I". Among them, the total score of students' gratitude is higher, which shows that college students have a higher tendency of gratitude. In each sub-scale, the score of density of gratitude is the highest $(20.42 \pm 2.57)$, followed by width $(12.27 \pm 1.96)$, frequency $(11.54 \pm 2.04)$, and the depth $(11.06 \pm 1.89)$. Density of gratitude refers to how many people one would appreciate after achieving success, such as parents, teachers, and friends and so on. The width of gratitude is the individual's gratitude to some aspects of life events, such as family, society, and life and so on. The frequency of gratitude refers to the frequency of the individual's experience of gratitude, and people with high frequency of gratitude will have the feeling of gratitude only because of some insignificant behavior; depth is the intensity of the experience of gratitude. In this survey, the score of density of gratitude is higher than those of other items. As far as college students are concerned, when they successfully enter the university, their roles in life have changed. In this process, many people have to be appreciated for their help, such as the careful care of parents, inculcation of teachers, and encouragement of friends and so on.

"Table II" shows the statistical result of whether there are differences in grade, grade, only child and other factors. The results of $\mathrm{T}$-test show that there is a significant difference between male and female $(\mathrm{P}<0.01)$ in frequency of gratitude, but there is no significant difference between male and female in the following three aspects: density, width and depth of gratitude For the depth of gratitude, the existing domestic research result shows that there is a significant 
difference in the gender factor in this dimension. The result of this study is not consistent with those of existing domestic researches. It is analyzed that the main reasons are differences in the sample selection process, sample size, control of unrelated factor, and the ratio of male to female and other factors. "Table II" also shows the difference test (T test) of the one-child factor in each dimension of gratitude, but the statistical result of this factor in each dimension is that all the factors do not reach a significant level of difference, which is consistent with the existing research results in China.

"Table III" shows the results of difference test of different grades in each dimension. After F-test, it is found that different grades reach a significant level of difference in each dimension. Among them, differences in the total score and width of gratitude are extremely significant $(\mathrm{P}<0.01)$, and the density, frequency and depth of gratitude also reach significant differences $(\mathrm{P}<0.05)$. Through multiple comparative LSD analysis, it is found that in terms of total scores of gratitude, the difference between freshmen and sophomores and junior students is significant, that between sophomores and senior students is significant, and that between junior students and senior students is significant; In the dimension density of gratitude, the difference between freshman and sophomore is significant, and the difference between sophomore and sophomore is significant. In the width dimension, the difference between freshman and sophomore and junior is significant. In the frequency dimension, the difference between freshman and sophomore and junior students is significant, and the difference between junior students and senior students is significant. In the depth dimension, the difference between freshman and sophomore and junior is significant. This further explains that there are differences the total score and all dimensions regarding different grades and the reasons causing psychological differences need to be further analyzed.

\section{B. Correlation Analysis of College Students' Gratitude, Adaptability and Coping Style}

TABLE IV. The Basic Situation of COllege Students ADAPTABILITY AND COPING STYLE

\begin{tabular}{cllc}
\hline & mean value & $\begin{array}{c}\text { standard } \\
\text { deviation }\end{array}$ & $\begin{array}{c}\text { Number } \\
\text { of items }\end{array}$ \\
$\begin{array}{c}\text { total score of adaptability } \\
\text { self-adaptation }\end{array}$ & 203.14 & 32.46 & 60 \\
emotional adaptation & 27.94 & 5.56 & 8 \\
learning adaptation & 37.62 & 4.90 & 9 \\
job selection adaptation & 30.36 & 7.58 & 11 \\
interpersonal adaptation & 33.68 & 6.13 & 9 \\
campus adaptation & 27.10 & 6.43 & 10 \\
degree of satisfaction & 16.06 & 5.33 & 8 \\
total score of coping style & 30.04 & 4.09 & 5 \\
rationalization factor & 4.35 & 6.44 & 62 \\
problem solving & 8.88 & 1.89 & 11 \\
fantasy factor & 4.23 & 2.53 & 11 \\
retreat factor & 4.24 & 2.13 & 10 \\
recourse factor & 5.76 & 2.24 & 11 \\
self-accusation factor & 3.27 & 2.39 & 10 \\
\hline
\end{tabular}

TABLE V. CORRELATION OF COPING STYLES IN VARIOUS DimENSIONS OF GRATITUDE

\begin{tabular}{|c|c|c|c|c|c|}
\hline & total score of gratitude & density of gratitude & width of gratitude & frequency of gratitude & depth of gratitude \\
\hline total score of coping style & -.019 & -.072 & -.011 & .074 & -.040 \\
\hline rationalization factor & $-.236 * *$ & $-.221 * *$ & $-.189 * *$ & $-.115^{*}$ & $-.248 * *$ \\
\hline problem solving & $.383^{* *}$ & $.184 * *$ & $.388 * *$ & $.358 * *$ & $.372 * *$ \\
\hline fantasy factor & $-.186^{* *}$ & $-.147 * *$ & $-.160 * *$ & -.092 & $-.217 * *$ \\
\hline retreat factor & $-.243 * *$ & $-.167 * *$ & $-.245 * *$ & $-.139 * *$ & $-.261 * *$ \\
\hline recourse factor & $.339 * *$ & $.230 * *$ & $.275^{* *}$ & $.282 * *$ & $.346^{* *}$ \\
\hline self-accusation factor & $-.289 * *$ & $-.205^{* *}$ & $-.276 * *$ & $-.204 * *$ & $-.279 * *$ \\
\hline
\end{tabular}

c. Note: $*$ indicates it is significant at 0.05 level. $* *$ indicates it is significant at 0.01 level.

TABLE VI. CORRELATION OF ADAPTABILITY IN EACH DIMENSION OF GRATITUDE

\begin{tabular}{|c|c|c|c|c|c|}
\hline & total score of gratitude & density of gratitude & width of gratitude & frequency of gratitude & depth of gratitude \\
\hline total score of adaptability & $.495 * *$ & $.305 * *$ & $.483 * *$ & $.439 * *$ & $.433 * *$ \\
\hline self-adaptation & $.365^{* *}$ & $.206^{* *}$ & $.380 * *$ & $.308 * *$ & $.337 * *$ \\
\hline emotional adaptation & $.472 * *$ & $.324 * *$ & $.445^{* *}$ & $.414 * *$ & $.389 * *$ \\
\hline learning adaptation & $.426 * *$ & $.236^{* *}$ & $.436 * *$ & $.383 * *$ & $.382 * *$ \\
\hline job selection adaptation & $.361 * *$ & $.222 * *$ & $.332 * *$ & $.303 * *$ & $.355^{* *}$ \\
\hline interpersonal adaptation & $.392 * *$ & $.297 * *$ & $.349 * *$ & $.347 * *$ & $.303^{* *}$ \\
\hline campus adaptation & $.405^{* *}$ & $.239 * *$ & $.411^{* *}$ & $.364 * *$ & $.348^{* *}$ \\
\hline degree of satisfaction & $.391 * *$ & $.204 * *$ & $.392 * *$ & $.383 * *$ & $.343^{* *}$ \\
\hline
\end{tabular}

${ }^{\text {d. }}$ Note: ** Indicates it is significant at 0.01 level

TABLE VII. REGRESSION ANALYSIS OF ADAPTABILITY AND GRATITUDE

\begin{tabular}{cllll}
\hline & $\begin{array}{c}\text { unstandardized } \\
\text { regression coefficient }\end{array}$ & $\begin{array}{c}\text { standardized } \\
\text { regression coefficient }\end{array}$ & T & P \\
\hline constant term & 75.552 & & 6.234 & .000 \\
\hline total score of gratitude & 2.308 & .495 & 10.610 & .000 \\
\hline
\end{tabular}

e. Note: The constant term is the intercept of regression line; Regression equation: Adaptability $=75.552+22.308 *$ Total score of gratitude 
From the results of "Table IV", it can be seen that the total scores of college students' adaptability, scores of each sub-scale and the total scores of coping style and scores of each sub-scale are within the theoretical value range, and the distribution of centralized trend and tendency of dispersion is well distributed, which can clearly describe the distribution characteristics of adaptability variable and coping style variable.

In analyzing the relationship between the dimensions of gratitude and the dimensions of coping style, it can be seen from the data in "Table V", the total score, density, width and depth of gratitude are negatively correlated with coping style, while there is a positive correlation between frequency of gratitude and coping style, but the correlation between variables is not significant. The regression equation between gratitude and coping style cannot be further established, and there is no prediction effect. In the correlation between various dimensions of gratitude and the six factors of coping style, it is found that the self-accusation factor and retreat factor are negatively correlated with the total score and the dimensions of gratitude $(\mathrm{P}<0.01)$. Problem-solving factor and recourse are positively correlated with total scores and each dimension of gratitude $(\mathrm{P}<0.01)$. There is a significant negative correlation between the rationalization factor and all the dimensions of gratitude, and the significant correlation between the rationalization factor and the frequency of gratitude is $\mathrm{P}<0.05$, and the significant correlation between the rationalization factor and the other three dimensions of gratitude is $\mathrm{P}<0.01$. There is a significant negative correlation $(\mathrm{P}<0.01)$ between the fantasy factor and the total score, the density, the width and the depth of gratitude $(\mathrm{P}<$ 0.01 ), but there is a negative correlation between the fantasy factor and the frequency of gratitude, and it does not reach a significant level. There is a positive correlation between gratitude and problem-solving and recourse. It can be understood that people with high gratitude tend to use positive ways to solve problems in the face of difficulties and in coping style, the ways of recourse will increase. Negative correlation with fantasy, retreat, self-accusation and other factors indicates that the individuals with the tendency of higher gratitude will rarely use fantasy, escape, selfaccusation and other ways to solve the problem in the face of difficulties.

In the analysis of the correlation between the dimensions of gratitude and adaptability, as shown in "Table VI", there is a significant positive correlation between the total scores and each dimension of adaptability, and the total scores of gratitude $(\mathrm{P}<0.01)$, which indicates that the individuals with a high tendency of gratitude adapt quickly in aspects of selfadaptation, emotional adaptation, learning adaptation, job selection adaptation, interpersonal adaptation, campus adaptation and have high degree of satisfaction with life and learning. On the other hand, the individuals with a low gratitude tend to adapt more slowly. In addition, by making further regression analysis between adaptability and gratitude as in "Table VII", the regression equation can be established between adaptability and gratitude (adaptability $=75.552 \sim$ $2.308 *$ the total score of gratitude), the linear correlation between the two variables of gratitude and adaptability is very significant and the fitting degree of the model is also very high. The regression equation is effective, and gratitude has a good prediction effect on the adaptability.

\section{CONCLUSION}

The results show that college students have good gratitude accomplishment, but it still needs to be further promoted. There are differences in gratitude psychology regarding different grades and different genders and the difference between male and female is significant. Especially in frequency of gratitude, he score of female is significantly higher than that of male. there is no difference between the only-child and non-only child; There is a correlation between gratitude and coping style, among which negative correlation exists between coping style and the density, width, and depth of gratitude, and there is positive correlation between coping style and frequency of gratitude. There is a significant positive correlation between gratitude and adaptability, and an effective regression equation is established. Gratitude has good predictive effect for adaptability. The study discusses the relationship between college students' gratitude, coping styles and adaptability, but due to the limited research ability and research conditions, there are still some deficiencies. In the choice of research tools and the process of measurement, the self-evaluation method of measured variable is used to control or reduce some irrelevant factors, but this cannot completely eliminate the error. In the sample selection, random sampling is adopted and differences in gender and grade are considered, but the age span of the objects is small, so it needs to be further improved to consider the influence of age on gratitude. In the analysis of the related factors, only the influence of gratitude on coping style and adaptability and correlation between them are considered, but there is no further analysis of the mediating variables, which need further study.

\section{REFERENCES}

[1] Jia Xiaobo. The Essence and Mechanism of Psychological Adaptation [J]. Journal of Tianjin Normal University (Social Science), 2001, 154 (1): 19. 贾晓波.心理适应的本质与机制 $[\mathrm{J}]$. 天津师范大学学报社 会版,2001,154(1):19.

[2] Chen Yu. Psychological adaptation and countermeasures of graduate students in colleges and universities [J]. Journal of Architectural Education Philosophy and Social Sciences Edition, 2005 (1): 165. 陈 瑜. 高校研究生的心理适应及对策 $[\mathrm{J}]$. 高等建筑教育哲学社会科 学版,2005(1):165.

[3] Zhang Lin, Che Wenbo, Li Bing. Study on the characteristics of coping style to psychological stress of college students [J]. Psychological Science, 2005 (1): 36. 张林, 车文博, 黎兵.大学生心理 压力应对方式特点的研究 [J].心理科学,2005 (1) : 36 .

[4] Dong Xuran, Tong Huijie. Relationship between coping style, coping efficacy and mental health of college students [J]. Science of Social Psychology, 2010 (4): 78. 董旭再, 童辉杰.大学生应对方式、应对效 能与心理健康的关系[J].社会心理科学, 2010(4):78.

[5] Fang Xiaoyi, Wo Jianzhong, Lin Xiuyun. Development of Chinese college students' adaptation scale [J]. Studies of Psychology and Behavior, 2005 (2): 95. 方晓义,沃建中, 蓶秀云.中国大学生适应量 表的编制 [J]. 心理与行为研究,2005(2): 95 .

[6] Xiao Jihua, Xu Xiufeng. Reliability and Validity of Coping Style Questionnaire [J]. Chinese Mental Health Journal, 1996 (4): 164. 肖 
计划, 许秀峰. 应对方式问卷信度与效度研究 [J]. 中国心理卫生杂 志,1996(4):164. 